\title{
Measurement of the Income Difference of Rural Residents in Peri-Urbanized Areas and Its Influencing Factors: Evidence from Nanhai, Foshan, China
}

\author{
Zhenhai Xiang ${ }^{1}$, Pengfei Ban ${ }^{1, *}$ and Qifeng Yuan ${ }^{2}$ \\ 1 School of Geography and Planning, Sun Yat-sen University, Guangzhou 510275, China; \\ xiangzhh@kust.edu.cn \\ 2 School of Architecture, South China University of Technology, Guangzhou 510006, China; \\ qfy510060@163.com \\ * Correspondence: banpf@mail2.sysu.edu.cn
}

Received: 21 August 2020; Accepted: 6 October 2020; Published: 12 October 2020

\begin{abstract}
This study supplements research on peri-urbanized areas by introducing a quantitative analysis of rural income inequality, with particular attention being paid to geographical causes. It also contributes a community/village-scale case to the current knowledge of the quantitative analysis of rural income inequality, which is mainly based on the county, municipal and higher levels. A typical peri-urbanized area in the Pearl River Delta-namely, Nanhai District, Foshan City-was considered as an empirical case. Based on 10-year continuous data, from 2007 to 2016, we first analyzed the distribution and spatial autocorrelation between per-capita share dividend income (PCSDI) and per-capita net income (PCNI). Then, we used a Geographically Weighted Regression (GWR) model to explore the strength and direction of the relationship between PCSDI and the five selected driving factors. The results show that, during the study period, the rural income difference of PCSDI in Nanhai generally narrowed, whereas the income difference of PCSDI generally expanded, and the spatial distribution of PCNI was more unequal than that of the PCSDI. The GWR model shows that geo-location (GL) has the strongest impact on PCSDI, followed by the per-capita area of state-owned land (PCASOL); the density of the road coverage (DRC) and the density of the registered population (DRP) have the least effect on PCSDI. Except for the per-capita area of collective constructive land (PCACCL), which is a global variable, the correlation between the four other factors and PCSDI is geographically uneven.
\end{abstract}

Keywords: peri-urbanized area; per capita share dividend income (PCSDI); per capita net income (PCNI); rural community; income inequality

\section{Introduction}

Since the Chinese economic reform, rural Chinese residents' income has achieved rapid growth, and people's living conditions have improved significantly. However, under the macro-background of nationwide, sustained, and rapid economic growth, the overall regional inequality of rural Chinese residents' income has continued upward, compared with that of urban residents [1-4]. The equality of rural Chinese residents' income has attracted the attention of economists, sociologists, human geographers, and other scholars. Compared with general rural areas, peri-urbanized areas are located on the edges of metropolitan cities. Given the advantages of their location, resources, history, and culture, peri-urbanized areas attract a large number of non-agricultural populations and industries, forming a special location between urban and rural areas with low land use efficiency, and drastic changes in economic and social development. Peri-urbanized areas also have distinct urban and rural dual characteristics [5-8]. In peri-urbanized areas, local residents exploit the non-agricultural 
development of collective land and the redevelopment of low-efficiency collective construction land to obtain land income. However, due to the ambiguous land property rights, the value-added income of the land has become the focus of interest of all of the relevant subjects, causing conflicts among stakeholders such as local villagers, developers, and government departments [9-11], e.g., the income and housing inequality between local and foreign residents [12-14]. All of these factors hinder the transition of peri-urbanized areas to full urbanization, thereby impeding their sustainable development in social, economic, and ecological aspects [15-17].

A large number of empirical studies on the peri-urbanized areas of specific cities and regions in developing countries have been conducted [16,18-23]. However, no consistent solution has been achieved to solve problem of the sustainable development of peri-urbanized areas. One of the main reasons for this is that peri-urbanization is a complex urban process which is affected by various factors, and which exhibits different characteristics in different countries. Since the 1980s, China has undergone rapid urbanization, and villagers have rushed into cities, making peri-urbanization occur and becoming the main driving force for city expansion in China in the 1990s [24]. Peri-urbanization is related to many environmental and social issues which have been verified in Chinese cities [25-28]. Specifically, income inequality is an important aspect. However, studies on inequality in peri-urbanized areas are relatively few. Certain scholars have mainly used qualitative methods on the basis of individual cases in order to reveal the inequal development situations in peri-urbanized areas, meaning that there is a lack of quantitative empirical research. Due to the limitation of the available data, the existing quantitative measurement of income inequality is mainly based on spatial analysis units at the county level, municipal level, and above; the community/village level analysis is relatively absent [29]. Furthermore, the causes of income inequality are mainly attributed to socioeconomic and institutional aspects, and in-depth discussions of geographical factors are insufficient.

The objective of this study is to accurately measure the evolution of the temporal and spatial differences in rural residents' incomes in peri-urbanized areas, and to reveal the influencing factors and mechanisms behind the differences, which are important in reducing the income gap, promoting the construction of a new countryside, and maintaining social stability. This study takes a typical peri-urbanized area in the Pearl River Delta—namely, Nanhai District, Foshan City-as an empirical case. Rural community residents' income is taken as the research object. PCSDI and PCNI are selected as measurement indicators, and the spatial autocorrelation model is used to measure the temporal and spatial evolution of the income differences in Nanhai rural communities from 2007 to 2016. A GWR model is also used to measure the key causes. The next section reviews the relevant literature related to the income disparities in rural communities. The third part introduces the background of the empirical area in detail. The fourth part presents the types and sources of the data used in the study, including the measurement models and methods. The fifth part summarizes and analyzes the research results. The sixth part discusses the related issues and the research conclusions.

\section{Literature Review}

Developed countries, such as the United States, Japan, South Korea, and countries in Western Europe, have achieved a high level of urbanization and are affluent, but have small rural populations. Thus, rural problems are not prominent, and research on rural inequality mainly focuses on developing countries [30-33]. Two classic theoretical models are often used to explain rural income inequality. The first one is the 'dual economic theory' of labor transfer in developing countries in the "Economic Development under the Condition of Unlimited Labor Supply" raised by Arthur Lewis, who believes that a society with a dual economic structure, due to several low-income labor forces in the traditional agriculture sector, and the continuous agricultural labor from rural to urban, is prompted until all the surplus labor in the agricultural sector is taken in by the industrial sector, and the dual economy becomes a single economy [34]. However, in some countries, not only a dual economic structure exists but also a dual system, which become the main obstacle for the transfer of agricultural labor and aggravates the income disparities in rural areas. This point has been highlighted by a large 
number of empirical studies in post-socialist countries, including China. The second model is the circular cumulative causality theory proposed by Myrdal. He believes that the economic expansion in a region can have two completely different effects on the surrounding regions: one is the echo effect. The economic expansion of the region leads to economic recession in the surrounding regions, and the income disparities among the regions continue to expand. The other is the diffusion effect. The difference between the diffusion effect and the echo effect is that the economic growth of a region also promotes and drives the economic progress and development of the surrounding regions. In this process, the income gap between regions gradually narrows [35]. This theory has good explanatory power for rural income disparities around large cities [36].

Specifically, the causes of rural income inequality are mainly due to three aspects. The first aspect is the policy reason. Starting from the relationship between farmers' income and the government agricultural allowance, government departments can greatly increase farmers' income through agricultural compensation, which has also conversely reduced the possibility of industrial transition [37,38]. The second aspect is the educational factor. The higher the education level that farmers reach, the more excellent employment opportunities they will have, and the more income they can obtain [39-41]. The third factor is the idea that the area of cultivated land and the quality of cultivated land positively affect the rural income difference [42,43].

In the early 1980s, income inequality among rural residents in China began to attract attention. Since 2005, the central policy has been to highlight the importance of the 'three rural issues'; thus, an increasing number of scholars have begun to turn to this field. Previous literature mainly focused on three aspects: (1) the quantitative analysis of Chinese rural residents' income variation trend. The data used mainly came from the statistical yearbook and household survey released by the government, and were based on the county level, prefecture-level city, and higher levels [44-46]. Moreover, Chinese rural residents' income inequality can be investigated from different scales or spatial levels, including the inland and coastal areas, the three belts (east, middle, and west), the urban and rural areas, the interprovincial areas, and the intra-provincial areas $[47,48]$. The literature survey shows that different spatial levels have not received the same degree of attention. The previous research tended to focus on the three belts and the provincial gap, and not the urban-rural gap to the same degree. In-depth discussions on the income differences of rural residents within cities or homogeneous regions are lacking. (2) Explaining the reasons of rural dwellers' income difference: from the perspective of income structure, most scholars believe that wage income or non-agricultural income is the main reason for the increment in rural income disparities in China, because non-agricultural activities are unevenly distributed in geographical space $[43,49,50]$. However, some scholars believe that non-agricultural income has a certain impact on rural income disparities from the overall perspective, but the specific impact level varies along the local economic development. The higher the value is, the greater the influence will be [51]. From the perspective of systems and policies, the population movement management system, national regional development strategy, price policy, and monetary policy are the major factors resulting in the income disparities of rural Chinese communities. In addition, studies have deeply explored the impact of family characteristics and geographic (location) factors on the rural income inequality in China. (3) There is also the urban-rural income gap, which is an important aspect of income inequality. Many studies have pointed out that, since the Chinese reform, China's urban-rural income has been enlarged, and the role of urban-rural income inequality on Chinese residents' overall income inequality has increased [52-54]. Regarding the reasons for the continuous expansion of the urban-rural income gap, scholars have different opinions [55,56].

With the transformation of China's urbanized development, new requirements have been proposed for the quality of this development, under which the limitations of existing research on rural income disparities are obvious. First, most of the available research results were obtained from economists and sociologists. Therefore, the causes of rural income disparities are mainly due to socioeconomic and policy conditions, and lack an in-depth exploration of geographical factors. Second, China has a vast territory, and large differences exist in the conditions of regional resource endowment. Existing 
studies that mainly focus on large-scale research in areas above the national and provincial levels lack in-depth discussions of small-scale spaces of homogeneous types of regions, such as peri-urbanized, poverty-stricken, and coastal areas. Finally, the existing quantitative measurement of income inequality is mainly based on spatial analysis units at the county, municipal, and higher levels, whereas those at the community/village scale are absent.

\section{Data and Methods}

\subsection{Empirical Area Background}

Nanhai was once a rural county of Foshan, which is the third largest city in the Pearl River Delta (the term 'Pearl River Delta' refers to the dense network of cities in South China, which includes nine prefectures of the province of Guangdong, namely Dongguan, Foshan, Guangzhou, Huizhou, Jiangmen, Shenzhen, Zhaoqing, Zhongshan and Zhuhai, and the SARs of Hong Kong and Macau), after Guangzhou and Shenzhen. In 2003, Nanhai became an urban district annexed to the Foshan municipality. Nanhai is located on the fringes of Guangzhou and Foshan, to the immediate west of the former and to the north of the latter's city proper (Figure 1). Given Nanhai's good location, it is becoming an economically and geographically dynamic district in the Pearl River Delta, and is forming a typical example for peri-urbanized areas.

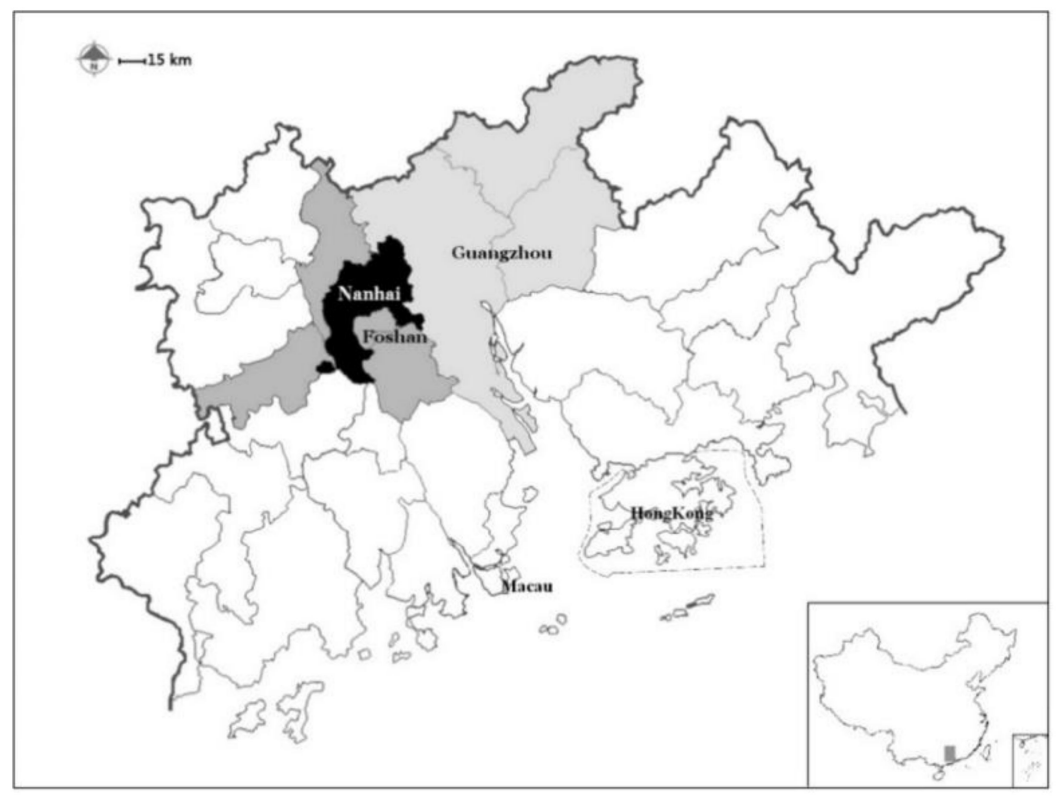

Figure 1. Location of Nanhai in the Pearl River Delta.

Since the 1990s, Nanhai has abandoned the high-risk and low-competition collective economic business model, and has turned to the formal or informal mode of land development to attract capital (especially foreign capital) $[57,58]$. To resolve the problem of farmland fragmentation under the household contract responsibility system, and in order to further improve the efficiency of land use, Nanhai has started the rural reform of the land shareholding cooperative system [57,59]. That is, villagers convert their land shares into shares by means of their land shares, and villagers obtain their shares free of charge. Village collectives establish cooperative organizations for rural shares. As the representatives of landowners, they are given the right to manage their land; villagers also obtain dividends according to their shares. Village collective organizations are responsible for managing and leasing land and property. Land rental income is divided into three parts: villagers' share dividends, rural public goods and welfare supply, and the village collective development fund, forming the 'lease economy' in which villagers and village collectives parasitize land and property (Figure 2). 


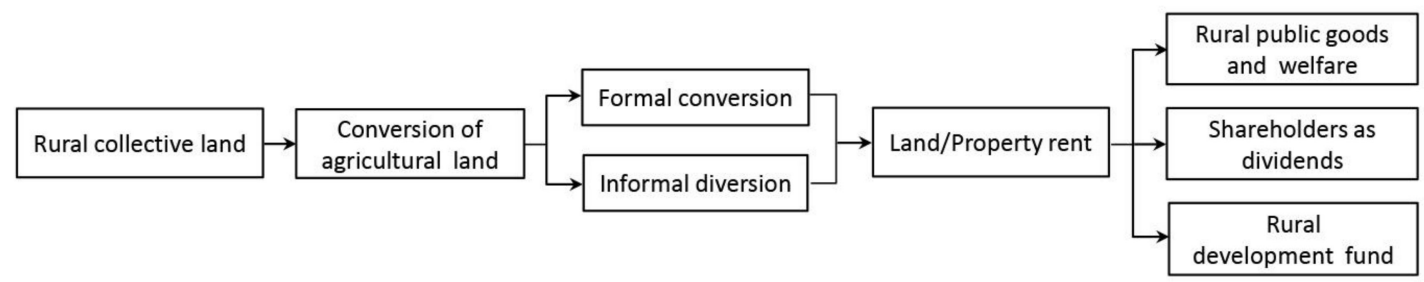

Figure 2. The income distribution pattern of residents in rural communities in Nanhai.

The process of rural industrialization and urbanization has led to a low cost and an unlimited expansion of construction land [60] (Figure 3). In 2008, the development of rural industrialization entered the connotative and intensive stage, revealing that the land development in the Pearl River Delta region had transitioned from quantity to quality, and from extensive incremental development to intensive stock renewal and re-development. Although the country has enforced the control of collective land development, and the land for construction in Nanhai accounts for a disproportionate share, with the extensive development model relying on the expansion of construction land in the past which no longer exists. Nevertheless, the income distribution model of the rental economy formed in the previous stage continues, which leads to income inequality among residents and the unequal pattern of income between local and foreign workers.
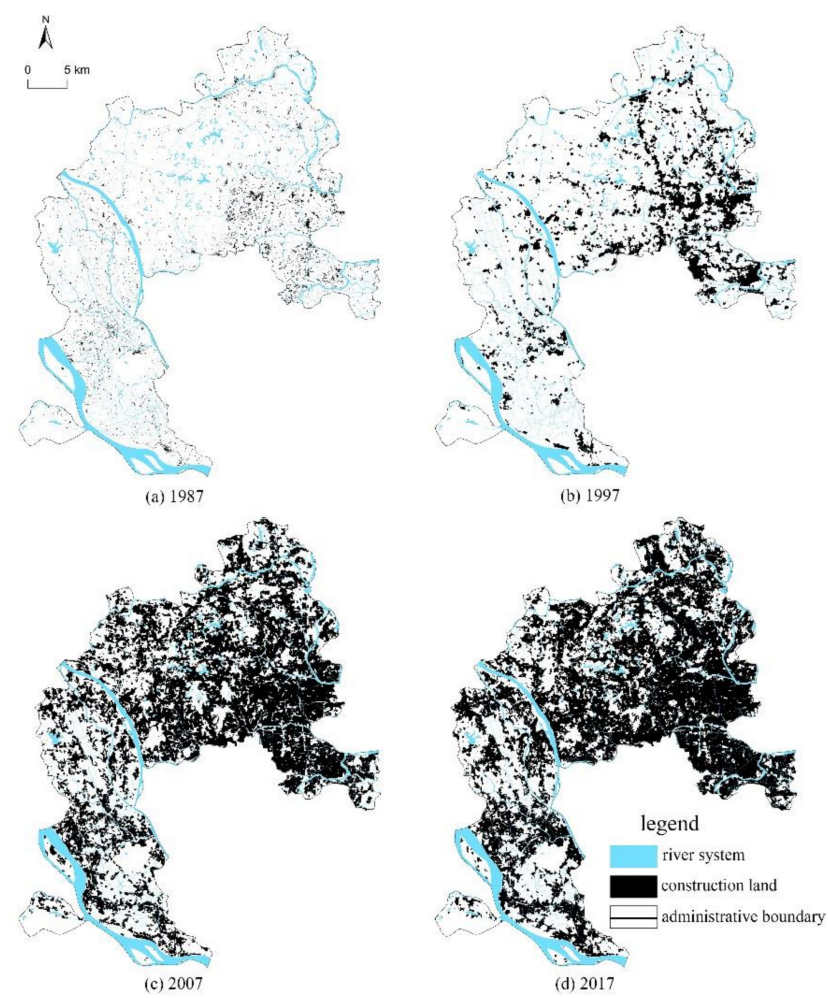

Figure 3. Growth of the built-up area in Nanhai: (a) 1987, (b) 1997, (c) 2007, and (d) 2017. Source: derived from satellite remote sensing maps at: datamirror.csdb.cn/admin/introLandsat.jsp.

\subsection{Data Sources}

In this study, the village (community) unit is taken as the basic unit to investigate the income difference and spatial pattern of rural community residents in the Nanhai District, Foshan City. The research indicators are the PCNI of rural residents and the PCSDI of the village community in each research unit, and the statistical data mainly, which is based on the Nanhai Collective Economic Statistics (2007-2016). The data on land types and ownership are mainly from the second land use 
survey of Nanhai District, and the map data primarily come from the Rural Work Department of Nanhai District. Considering the changes of the administrative units over the 10 years, some administrative units have been merged or split in order to maintain the consistency of the administrative units for the convenience of measurement. Finally, seven towns/streets and 211 villages were obtained (Figure 4).

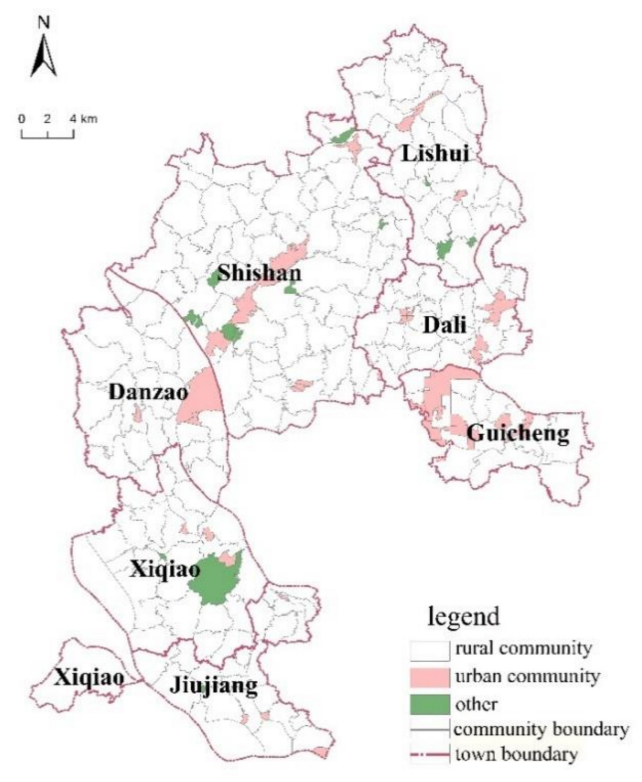

Figure 4. Community types in Nanhai.

\subsection{Influencing Factors}

In general, the income of the rural residents in Nanhai is mainly composed of wage income, land share dividend income, and house lease income, the average proportions of which are $49 \%, 35.3 \%$, and $15.7 \%$, respectively. According to the interviews in several villages of Nanhai, the wage income gap among villagers is relatively small. As village collectives often require village people to be employed preferentially, compared with the labor force of migrant workers, village residents tend to occupy better jobs with relatively high and average wages. Although obtaining specific data on residents' rental income is impossible, PCSDI and housing rental income are positively correlated. Therefore, the income inequality of rural residents is mainly reflected in the gap of the land income, and the GWR of PCSDI are used to represent the main factors. The five factors-GL, DRP, the coverage of the highway area, the amount of collective construction land per capita, and the amount of state-owned land per capita-were applied to the GWR model. Table 1 shows the statistical information for each of the variables, including the expected directions in accordance with the perception of the practical experience.

Table 1. Statistical summary of the variables.

\begin{tabular}{|c|c|c|c|c|c|c|}
\hline Variable Definition & Symbol & $\begin{array}{l}\text { Expected } \\
\text { Direction }\end{array}$ & Minimum & Maximum & Mean & $\begin{array}{c}\text { Standard } \\
\text { Deviation }\end{array}$ \\
\hline Geo-Location (km) & GL & - & 7.41 & 39.26 & 20.77 & 7.48 \\
\hline $\begin{array}{l}\text { Density of Registered } \\
\text { Population (per/ha) }\end{array}$ & DRP & + & 2.29 & 38.95 & 8.68 & 5.31 \\
\hline Density of Road Coverage (\%) & DRC & + & 0 & 0.17 & 0.04 & 0.03 \\
\hline $\begin{array}{l}\text { Per Capita Area of Collective } \\
\text { Constructive Land (ha) }\end{array}$ & PCACCL & + & 121.30 & 1923.27 & 533.25 & 310.18 \\
\hline $\begin{array}{l}\text { Per Capita Area of } \\
\text { State-Owned Land (ha) }\end{array}$ & PCASOL & - & 0.19 & 1560.35 & 250.65 & 288.83 \\
\hline
\end{tabular}

Source: the data on the five drivers listed above (i.e., DRP, GL, DRC, PCACCL, and PCASOL) were derived from the Second Land Use Survey of Nanhai District. 
GL: GL determines the value of land and property, which is the key factor in shaping the income inequality of rural residents. Specifically, the closer the land is to the urban areas of Guangzhou and Foshan, the higher the land's value will be. Therefore, the arithmetic square root of the distance from each rural area to the center of Guangzhou (marked by the Guangzhou Municipal government) and the center of Foshan (marked by the Foshan municipal government) was adopted as the location factor of each rural area.

DRP: this index reflects the amount of land resources per capita, which is the background condition of the space occupied by each village. It is also the historical cause of the difference in villagers' income under the non-agricultural development of collective land.

DRC: roads (especially highways) are important for industrial development. Thus, the density of highway coverage can be an indicator for the evaluation of the development condition of villages.

PCACCL: village collectives obtain income by leasing land and property. Therefore, in the context of the era in which the state strictly controls the conversion of farmland and the renewal of the existing construction land, the amount of the existing collective construction land becomes an important basis for the bonus income level of villagers.

PCASOL: Contrary to the above indicators, land expropriation by the government reduces the collective land resources of the village, thus reducing the sustainable income of villagers, even though the land-expropriated villagers can receive a substantial amount of compensation at that time.

\subsection{Methods}

\subsubsection{Spatial Autocorrelation Modeling}

According to the First Law of Geography, the observed data of the variables in the region have a certain degree of interdependence, and the closer the distance is to the space, the stronger the dependence [61]. Rural residents' incomes in peri-urbanized areas also have a spatial autocorrelation. This study uses Global Moran's I in order to inspect the spatial autocorrelation of rural residents' income in Nanhai. When the exponent of Global Moran's I is larger than 0, the spatial autocorrelation is positively autocorrelated; the larger the value is, the stronger the cluster feature will be. When the exponent of Global Moran's I is smaller than 0, the relationship is inversely spatially autocorrelated; the smaller the value is, the more balanced the geographical distribution of rural residents' income will be. The formula of Global Moran's I is as follows [62]:

$$
\mathrm{I}=\left[\frac{\mathrm{n}}{\sum_{i} \sum_{j} w_{i j}}\right]\left[\frac{\sum_{i} \sum_{j} w_{i j}\left(x_{i}-\bar{x}\right)\left(x_{j}-\bar{x}\right)}{\sum_{i} \sum_{j}\left(x_{i}-\bar{x}\right)^{2}}\right]
$$

where $I_{i}$ represents the value of the Local Moran's I; $z_{j}$ is the number of regional units; $x_{i}$ is the income of rural $i$; and $\bar{x}$ is the average income of all rural residents.

In order to ensure the group range and features of the rural residents' income spatial cluster, the exponent of Local Moran's I is used to identify the heterogeneity of the rural residents' income spatial differences, in order to fully reflect the trend of regional spatial differences. At a certain significance level, the villagers are divided into four spatial autocorrelation relationships: when Moran's I index is significantly positive and the $\mathrm{Z}$ value is greater than 0 , it is a 'high-high $(\mathrm{H}-\mathrm{H})$ agglomeration', indicating that the income of rural residents in the research and adjacent units is high. When Moran's I index is significantly positive and $\mathrm{Z}$ value is less than 0 , it is a 'low-low $(\mathrm{L}-\mathrm{L}$ ) agglomeration,' suggesting that the income of rural residents in the research and the adjacent units is low. When Moran's I index is significantly negative and the $\mathrm{Z}$ value is greater than 0 , 'high-low $(\mathrm{H}-\mathrm{L})$ agglomeration,' indicating that high-value units are surrounded by low-value units. When Moran's I index is significantly negative and $\mathrm{Z}$ value is less than 0 , it is a 'low-high (L-H) agglomeration,' suggesting that the low-value units 
are surrounded by high-value units. It is randomly distributed when $\mathrm{Z}$ is equal to 0 . The formula of the Local Moran's I exponent is as follows:

$$
I_{i}=z_{i} \sum_{i} w_{i j} z_{j}
$$

where $I_{i}$ represents the value of the local Moran's I; $z_{i}$ and $z_{j}$ are the numbers of the regional units; $x_{i}$ is the income of rural $i$; and $\bar{x}$ is the average income of all of the rural residents.

\subsubsection{GWR Modeling}

GWR models are superior to traditional regression models, such as ordinary least squares, because they support the calculation of a parameter estimate of the local variations in the association between the independent and dependent variables, rather than a global regression. In comparison, global regression models can obscure potential relationships in local variations. The form of a GWR model is as follows:

$$
y_{i}=\beta_{0}\left(u_{i}, v_{i}\right)+\beta_{1}\left(u_{i}, v_{i}\right) x_{i 1}+\beta_{2}\left(u_{i}, v_{i}\right) x_{i 2}+\cdots+\beta_{k}\left(u_{i}, v_{i}\right) x_{i k}+\varepsilon_{i}
$$

where $y_{i}$ is the dependent variable; $i$ denotes the rural communities in the study area; the five drivers, DRP, GL, DRC, PCACCL, and PCASOL, are denoted by $x_{i k}(k=1, \ldots, 5)$ in the model; $\beta_{k}$ is the estimated coefficient; $\left(u_{i}, v_{i}\right)$ is the location of observation $i$; and $\varepsilon_{i}$ is the random error term.

The communities near a given community are more important to it than remote communities, indicating that the characteristic values of adjacent points affect the characteristic values of a certain point in space. This influence gradually decreases as the distance between the two communities increases. The weight value therefore follows a bell curve based on distance. A weight matrix represents the relative importance between the communities. The estimated coefficient can be calculated by the following matrix form, where $T$ represents the matrix transpose operation:

$$
\hat{\beta}=\left(X^{T} W_{i} X\right)^{-1} X^{T} W_{i} y
$$

where $\hat{\beta}$ is the estimated coefficient of regression community $i$; $X$ is a matrix of independent variables; $X^{T}$ is the matrix transpose operation for matrix $X ; W_{i}$ is the weight matrix of the regression community $i$; and $y$ is the dependent variable.

Moreover, $W_{i}$ is a diagonal weighting matrix, as follows:

$$
W_{i}=\left[\begin{array}{cccc}
w_{i 1} & 0 & L & 0 \\
0 & w_{i 2} & 0 & 0 \\
\vdots & \vdots & \cdots & \vdots \\
0 & 0 & \cdots & w_{i n}
\end{array}\right]
$$

where $W_{i}$ is a diagonal matrix whose $w_{\text {in }}$ entries define the geographic field for each location $i$. The weights are chosen such that those $n$ observations nearby a given location in geographic space, where the parameter estimates are to be computed, have more influence on an estimation result than do observations located further away.

Ranges, also called 'bandwidths,' are decided upon and determine the number of nearby communities that should be included in a given weight matrix. Bandwidths are a key part of the modeling process, as communities vary in terms of area. In this study, we chose an adaptive kernel in order to select the optimal number of neighboring communities according to the Akaike Information Criterion (AIC), which is considered the most appropriate index to find the most appropriate number of neighbors of a regression community. The spatial radius of the regression community matches the 
density of the communities at each regression location. A bi-square weighting function was selected in order to obtain the weight between the communities; such a function is calculated as follows:

$$
W_{i j}=\exp \left(-\left(\frac{d_{i j}}{b}\right)^{2}\right)
$$

where $W_{i j}$ refers to the impact between position $i$ and position $j ; d_{i j}$ denotes the geographical distance between regression community $i$ and observation community $j$; and $b$ is the bandwidth. The larger bandwidth $b$ is, the slower the weight influence decreases as distance $d_{i j}$ increases; the smaller bandwidth $b$ is, the faster the weight influence decreases as distance $d_{i j}$ increases. The optimal bandwidth distance can be obtained automatically by the software tool GWR4.

\section{Results}

\subsection{Features of Rural Residents' Income Difference}

\subsubsection{The General Situation and Spatial Pattern of Rural Residents' Income Differences}

Figure 5 illustrates that, in general, the rural PCSDI and PCNI in Nanhai increased remarkably in the years 2007-2016. However, PCSDI had a more rapid increment, that is, more than 2.5 times from 2124 RMB to 5346 RMB from 2007 to 2016, and had a $6.0 \%$ average annual growth rate, compared to PCNI increasing from 10,359 RMB to 22,276 RMB from 2007 to 2016 and achieving up to a 2.2 times increment and a 5.3\% average annual growth rate. The reason is that the state strengthened the strict control over the development of construction land. Specifically, construction land in Nanhai tends to be saturated, which aggravates the scarcity of construction land, leading to the rapid rise of land rent and the fast-paced growth of PCSDI concomitantly.

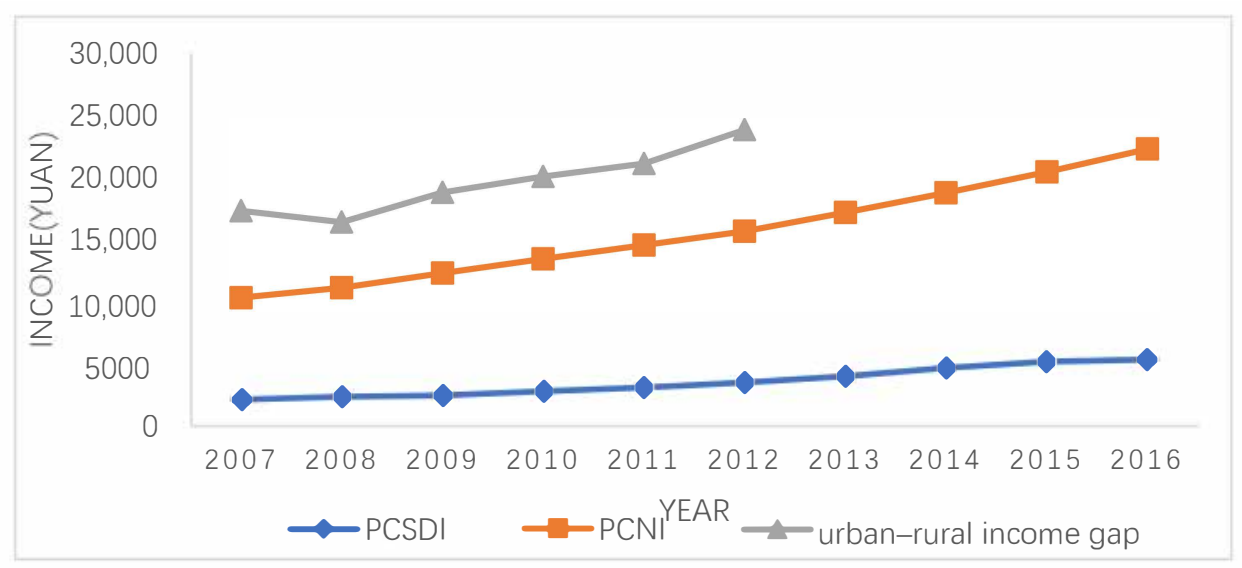

Figure 5. Rural residents' incomes in Nanhai. Source: the PCSDI and PCNI data were derived from the Nanhai Collective Economic Statistics (2007-2016), and the urban-rural income gap data were from the Nanhai Statistical yearbook (2008-2013).

In terms of the urban-rural income gap, except for 2008, the disparity kept expanding, suggesting that the income gaps between the rural and urban residents in Nanhai failed to narrow from rural industrialization (more precisely, non-agricultural development).

In order to show the difference in the spatial distribution and make a comparison, the PCSDI and PCNI of 2007 and 2016 are simply calculated (Table 2). The result indicates that, from the perspective of PCNI, regardless of the year (2007 or 2016), PCNI is the highest in eastern towns, followed by western towns, and the lowest in central towns; the average annual growth rate is the fastest in the west, second in the east, and the slowest in the central area. Down to the towns during this period, ranking in the top three were always Guichen, Dali, and Xiqiao, because the east part of Nanhai borders the 
downtown of Guangzhou. The development of land de-agriculturalization there came into force early; it has now transformed into a service function area for businesses and offices, giving local residents high incomes.

Table 2. Spatial distribution characteristics of the incomes of rural residents in Nanhai from 2007 to 2016.

\begin{tabular}{|c|c|c|c|c|c|c|c|c|c|c|c|c|c|}
\hline & & \multicolumn{6}{|c|}{ PCSDI (¥:Yuan) } & \multicolumn{6}{|c|}{ PCNI (¥:Yuan) } \\
\hline & & \multicolumn{2}{|c|}{2007} & \multicolumn{2}{|c|}{2016} & \multicolumn{2}{|c|}{$\begin{array}{l}\text { Growth } \\
\text { Rate }(\%)\end{array}$} & \multicolumn{2}{|c|}{2007} & \multicolumn{2}{|c|}{2016} & \multicolumn{2}{|c|}{$\begin{array}{l}\text { Growth } \\
\text { Rate (\%) }\end{array}$} \\
\hline \multirow{3}{*}{$\begin{array}{l}\text { Eastern } \\
\text { Towns }\end{array}$} & Guicheng & 2893 & \multirow{3}{*}{2796} & 6754 & \multirow{3}{*}{7305} & 13.4 & \multirow{3}{*}{16.1} & 11,677 & \multirow{3}{*}{10,047} & 23,483 & \multirow{3}{*}{20,326} & 10.1 & \multirow{3}{*}{10.2} \\
\hline & Dali & 3864 & & 9900 & & 15.6 & & 11,039 & & 21,297 & & 9.3 & \\
\hline & LIshui & 1905 & & 5545 & & 19.1 & & 8426 & & 17,935 & & 11.3 & \\
\hline Central & Shishan & 1886 & \multirow{2}{*}{1656} & 4975 & \multirow{2}{*}{4363} & 16.4 & \multirow{2}{*}{16.3} & 8308 & \multirow{2}{*}{8485} & 14,877 & \multirow{2}{*}{16,457} & 7.9 & \multirow{2}{*}{9.4} \\
\hline Towns & Danzao & 1087 & & 2844 & & 16.2 & & 8923 & & 20,374 & & 12.8 & \\
\hline Western & Jiujiang & 1543 & \multirow{2}{*}{1407} & 2764 & \multirow{2}{*}{2964} & 7.9 & \multirow{2}{*}{11.1} & 8068 & \multirow{2}{*}{9122} & 18,872 & \multirow{2}{*}{20,437} & 13.4 & \multirow{2}{*}{12.4} \\
\hline Towns & Xiqiao & 1286 & & 3141 & & 14.4 & & 10,055 & & 21,822 & & 11.7 & \\
\hline
\end{tabular}

Source: the PCSDI and PCNI data were derived from the Nanhai Collective Economic Statistics (2007-2016).

Although Xiqiao is located in the west zone, the farthest from Guangzhou, Xiqiao embraces a unique natural environment and grand resources, such as Xiqiao Mountain and the Mulberry fish pond. In the agricultural era, the Mulberry fish pond was more valuable than general farmland. At the later stage of the rapid urbanization in the east zone, this area continuously conserved environmental resources, developed the tourism and leisure industry, and positioned itself as the backyard of the Guangzhou-Foshan metropolitan region with huge success. Although Danzao and Jiujiang had weak locational conditions and local resources at the initial stage, and had the lowest income, their advantages started to stand out when other areas with earlier development faced the problem of shortage of land. Several processing, manufacturing, logistics, and warehousing enterprises came to lease land to operate, and PCNI increased rapidly, meaning that they became the two towns with the fastest growth.

PCSDI is the highest in eastern towns, and is higher in central towns than in western towns. In terms of the average annual growth rate, eastern towns are close to the central zone, with $16.3 \%$ and $16.1 \%$, respectively. Western towns are the farthest, with only $11.1 \%$. On the level of each town during this period, ranking in the top three are Dali, Guicheng, and Lishui, also resulting from the advantages of their geographical position. However, a small difference can be observed; that is, Guicheng has the best geographical position, but the dividend income here is not the highest, because in the early 1990s, Guicheng, as the center of Nanhai, was developed on a massive scale. Many farmlands were requisitioned by the government and, today, the remaining collective construction land is limited. This part will be further explained in detail later. Danzao, Xiqiao, and Jiujiang rank at the end. However, Xiqiao ranked first among the three towns, with the same reason as previously stated in 2016. Under the weakness of geographical position, Xiqiao actively connects itself with Guangzhou-Foshan Metropolitan regions in order to promote its industries on the basis of the beautiful natural environment and culture, enabling its land value to increase with a super curve. Meanwhile, Shishan has been set as the National Development Zone and the key investment zone of Nanhai district government since 2009 , meaning that the town developed to a large scale and become the fastest growing town.

\subsubsection{The Spatial Correlation and Clustering Features of the Rural per Capita Income}

The spatial autocorrelation measurement model was used to further analyze the spatial correlation and agglomeration features of PCSDI and PCNI in Nanhai. Queen's connectivity technology was applied to create spatial weights for the calculation of the Moran index, indicating the two targets during each year, and for the generation of the Moran scatter plots (Table 3, Figures 6 and 7). The results reveal that, first, the spatial distribution of PCSDI and PCNI in Nanhai rural communities showed significant spatial clustering features during the 2007-2016 period. The spatial cluster of PCNI was also remarkably higher than that of PCSDI, suggesting that the spatial distribution of PCNI was 
more unequal than PCSDI. Second, the overall clustering trend of the spatial distribution of the rural communities' PCSDI in Nanhai went downward. The Moran's I decreased from 0.4099 in 2007 to 0.3191 in 2016; that is, a 22.2\% decrease. Contrarily, the spatial distribution of the clustering PCNI decreased slightly in 2014 and 2015, and kept increasing in all of the other years. The Moran's I was 0.4517 in 2007, and increased to 0.6241 in 2016 with $38.2 \%$, which indicates that the PCSDI disparity narrowed down, whereas the net income gap continued to enlarge. The reason may be that, on the one hand, with the development of the integration of the Guangzhou-Foshan metropolitan area, the internal location difference of Nanhai, which is located at the edge of the metropolitan area, is becoming increasingly flat, and the PCSDI difference associated with land rent value tends to become narrow. On the other hand, with the upgrading of industries, those in different geographical locations in Nanhai are becoming increasingly diversified, which leads to the expansion of the wage income difference. Therefore, the difference of the PCNI shows an expanding trend in general.

Table 3. The Moran's I of the per capita income of rural community residents from 2007 to 2016.

\begin{tabular}{ccccccccc}
\hline \multirow{2}{*}{ Year } & \multicolumn{9}{c}{ PCSDI } \\
\cline { 2 - 9 } & Moran's I & SD & Z-VALUE & P-VALUE & Moran's I & SD & Z-VALUE & P-VALUE \\
\hline 2007 & 0.4099 & 0.0457 & 9.0533 & 0.001 & 0.4517 & 0.0445 & 10.1869 & 0.001 \\
2008 & 0.4231 & 0.0463 & 9.2486 & 0.001 & 0.5415 & 0.0462 & 11.8200 & 0.001 \\
2009 & 0.4399 & 0.0458 & 9.7654 & 0.001 & 0.5464 & 0.0464 & 11.8726 & 0.001 \\
2010 & 0.3880 & 0.0452 & 8.6691 & 0.001 & 0.5622 & 0.0479 & 11.8250 & 0.001 \\
2011 & 0.3534 & 0.0466 & 7.6701 & 0.001 & 0.5786 & 0.0467 & 12.4553 & 0.001 \\
2012 & 0.3528 & 0.0479 & 7.4609 & 0.001 & 0.5844 & 0.0453 & 12.9894 & 0.001 \\
2013 & 0.2972 & 0.0472 & 5.9841 & 0.001 & 0.5920 & 0.0478 & 12.5068 & 0.001 \\
2014 & 0.3145 & 0.0461 & 6.9074 & 0.001 & 0.5719 & 0.0454 & 12.6205 & 0.001 \\
2015 & 0.2983 & 0.0465 & 6.4825 & 0.001 & 0.5302 & 0.0488 & 10.9648 & 0.001 \\
2016 & 0.3191 & 0.0459 & 7.0908 & 0.001 & 0.6241 & 0.0435 & 14.4450 & 0.001 \\
\hline
\end{tabular}

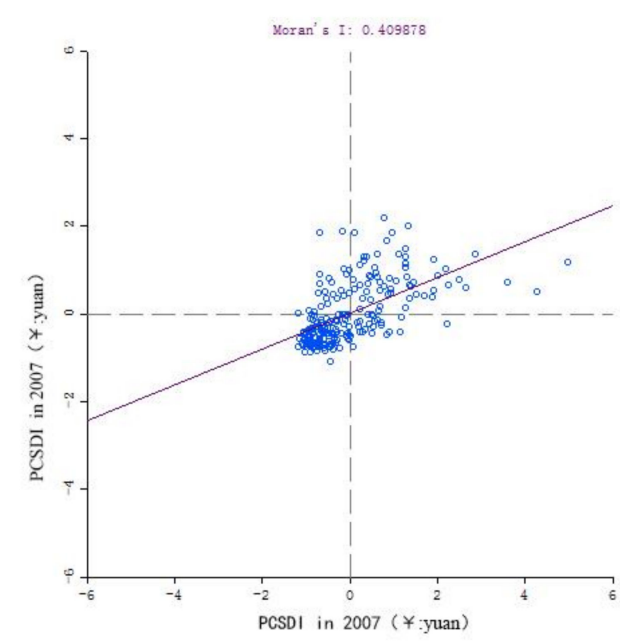

(a)

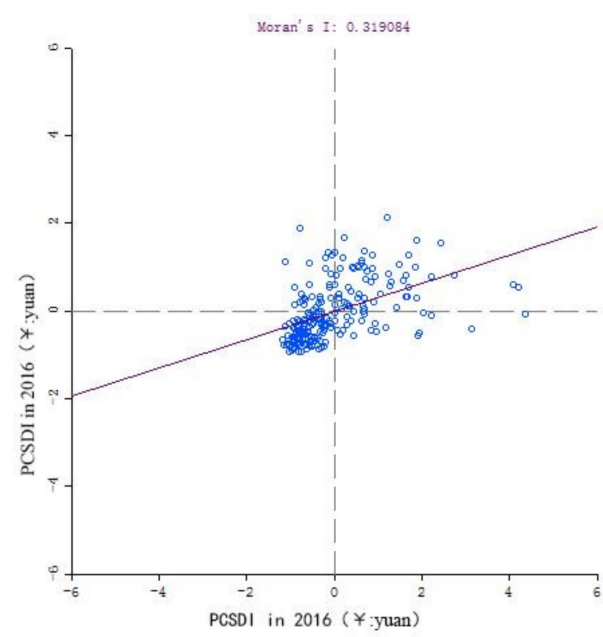

(b)

Figure 6. (a) Moran Scatter chart of the rural community residents' PCSDI in 2007, (b) Moran Scatter chart of the rural community residents' PCSDI in 2016. 


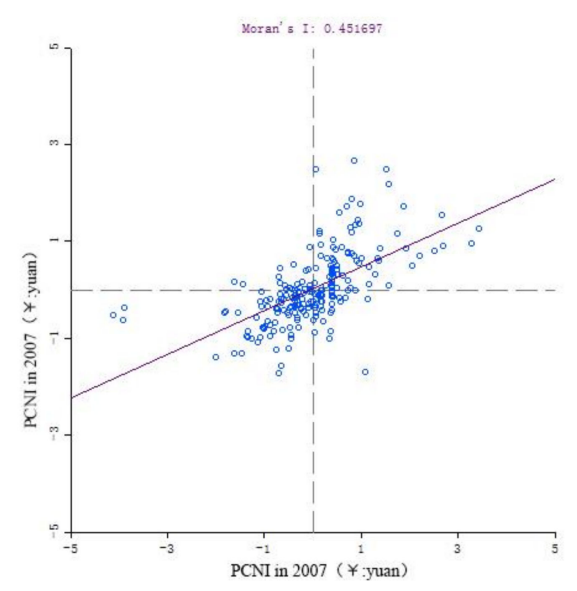

(a)

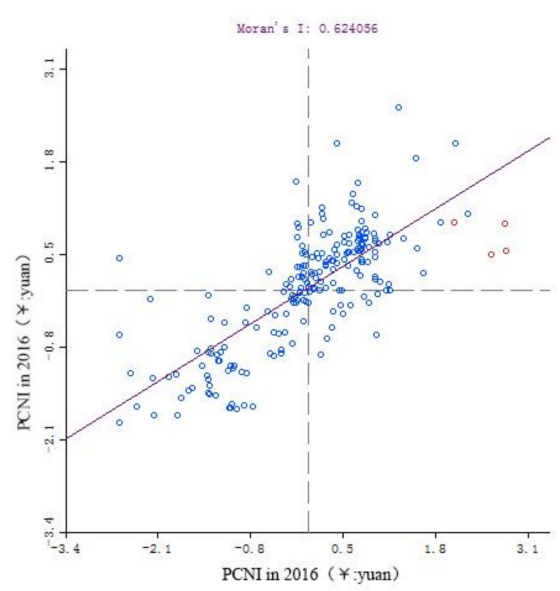

(b)

Figure 7. (a) Moran Scatter chart of the PCNI of the rural community residents in 2007, (b) Moran Scatter chart of the PCNI of the rural community residents in 2016.

Based on these results, a Local Moran's I was adopted in order to evaluate the feature of the local spatial autocorrelation evolution of rural communities' per capita incomes (Figures 8 and 9). Both figures show that: (1) H-H and L-L units with significant PCSDI in 2007 are roughly balanced, at 25 and 28, respectively. Among them, the $\mathrm{H}-\mathrm{H}$ districts are mainly taken up by the south of Dali and Shishan, whereas the L-L districts are mainly taken up by the northeast part of Shishan, Lishui, and Danzao Town. Outstanding changes occurred in 2016. Outstanding $\mathrm{H}-\mathrm{H}$ units decreased by five, whereas outstanding L-L units increased by nine. The overall outstanding areas decreased by seven, indicating that the overall dividend disparity was reduced, and the main reason for the reduction was the reduction of the $\mathrm{H}-\mathrm{H}$ units. Nevertheless, $\mathrm{H}-\mathrm{H}$ districts are still mainly taken up by the southern part of Dali and Shishan, but the latter accounts for more with the former's decrease. The L-L area is mainly concentrated in the northeastern part of Danzao, Xiqiao, and the southeast corner of Jiujiang Town. (2) H-H units with outstanding PCNI in 2007 have an obvious advantage over L-L units, with 13 more units. $\mathrm{H}-\mathrm{H}$ districts are mainly concentrated in Dali and Guicheng, whereas L-L districts are mainly concentrated in the north of Shishan and Lishui Town. Outstanding changes took place in 2016, resulting in $\mathrm{L}-\mathrm{L}$ units outperforming $\mathrm{H}-\mathrm{H}$ units, with seven additional units. Overall, outstanding regions increased by 31, of which $\mathrm{H}-\mathrm{H}$ units increased by 5 and $\mathrm{L}-\mathrm{L}$ units increased by 25 , indicating that the increment of L-L units gave rise to the enlargement of the overall PCNI inequality. In addition to Dali Town and Guicheng Street, Xiaoqi was included in the $\mathrm{H}-\mathrm{H}$ cluster, and the number of units in Dali Town was significantly reduced. The L-L cluster is largely found in the north of Shishan Town and Lishui Town. 

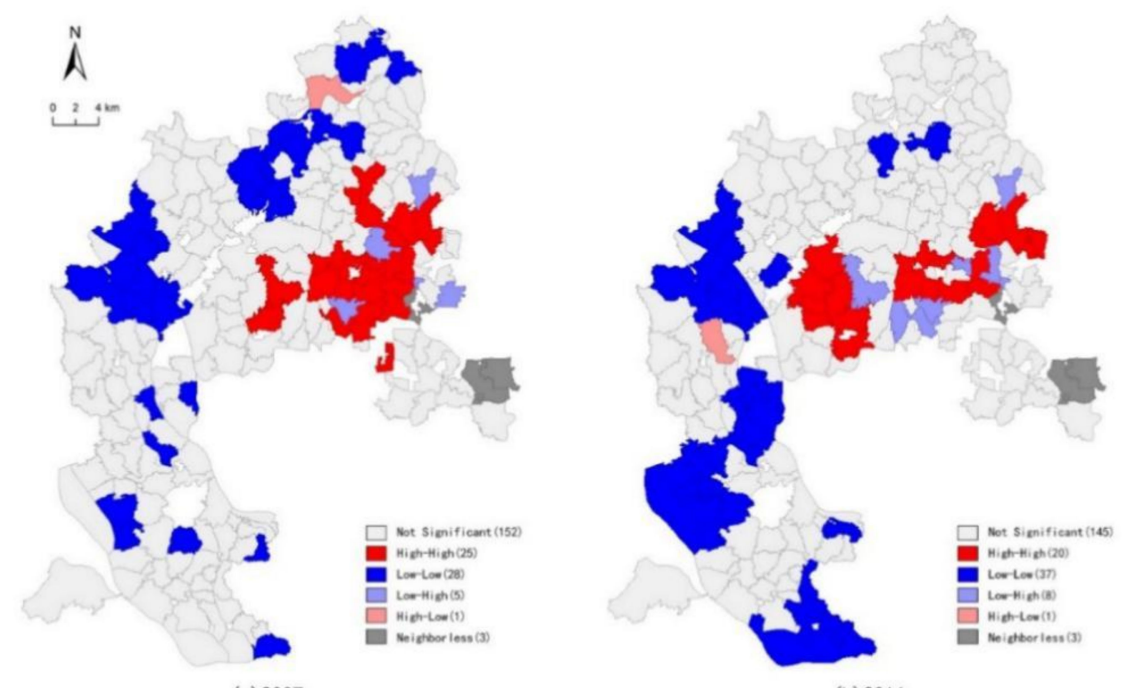

(a) 2007

(b) 2016

Figure 8. (a) Local spatial autocorrelation cluster chart of the rural residents' PCSDI in 2007, (b) Local spatial autocorrelation cluster chart of the rural residents' PCSDI in 2016.

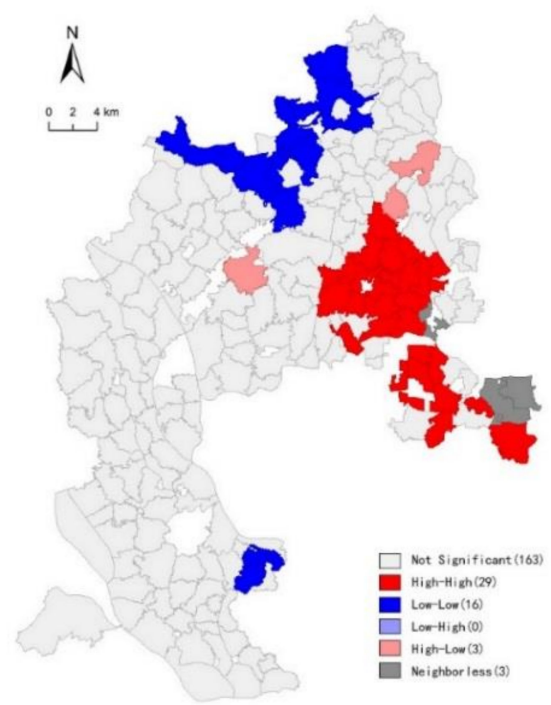

(a) 2007

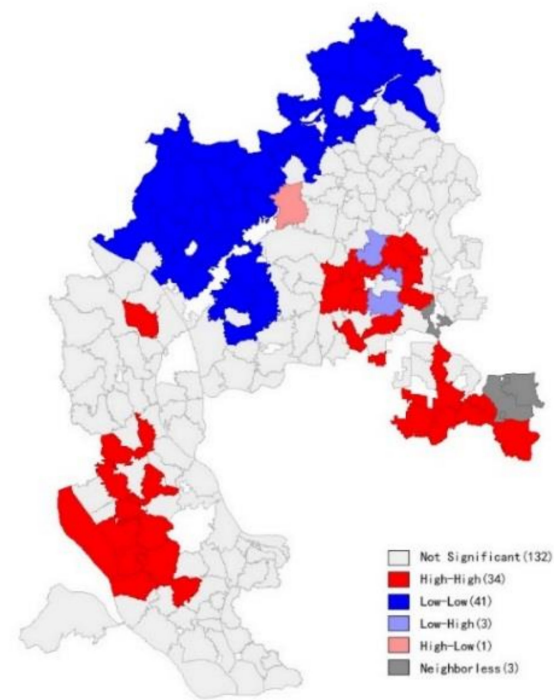

(b) 2016

Figure 9. (a) Local spatial autocorrelation cluster chart of PCNI of the rural residents in 2007, (b) Local spatial autocorrelation cluster chart of PCNI of the rural residents in 2016.

\subsection{Factors Influencing the Income Difference of Rural Residents}

\subsubsection{Analysis of the GWR Result}

In order to improve the spatial difference of rural communities' PCSDI in Nanhai District, this study used GWR to explore the spatial heterogeneity of factors affecting PCSDI. The abovementioned influencing factors involve five indicators, which are DRP, GL, DRC, PCASOL and PCACCL. In order to avoid the deviation of the estimation results caused by the mutual influence between the indicators, a collinearity test was conducted. The results are presented in Table 4, which shows that the values of the variance expansion factor of the indicators in the collinearity results are all less than 10 , and the conditional indexes are all less than 30 , suggesting that no collinearity exists in the index selected in this study. 
Table 4. Collinearity inspection of the five influential factors.

\begin{tabular}{cccc}
\hline & VIF & Eigenvalue & Condition Index \\
\hline GL $(\mathrm{km})$ & 1.741 & 0.646 & 2.666 \\
DRP (per/ha) & 2.499 & 0.376 & 3.496 \\
DRC (\%) & 1.259 & 0.219 & 4.583 \\
PCASOL (ha) & 1.427 & 0.151 & 5.510 \\
PCACCL (ha) & 1.326 & 0.014 & 17.874 \\
\hline
\end{tabular}

Figure 10 illustrates the $\mathrm{R}^{2}$ spatial distribution of the matching degree on the basis of the processing results of the GWR model, which mainly exhibits the matching level between the indicators selected by the GWR model and the actual rural PCSDI. The results reveal that the $\mathrm{R}^{2}$ of each community is distributed between 0.25 and 0.81 . The $\mathrm{R}^{2}$ in Danzao and Lishui is larger than that in Guicheng Street, Dali Town, and Xiqiao Town. After the test was conducted, LG, DPR, DRC, and PCASOL had a spatial variability in the impact of PCSDI, and could theefore be set as local variables. PCACCL leaves a little influence on per capita dividend distribution, and thus was set as a global variable.

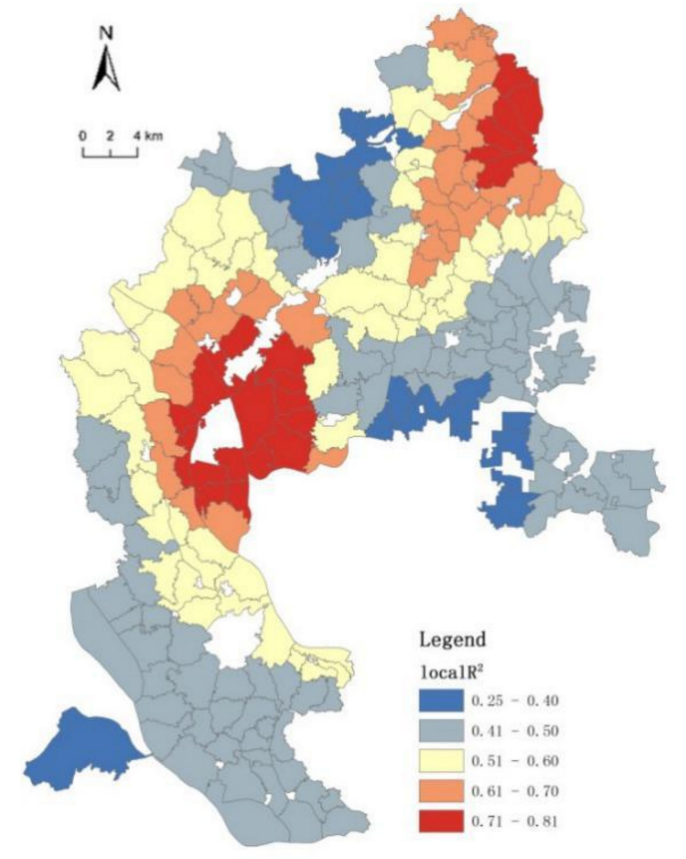

Figure 10. R-square values derived from the GWR model.

Using the adaptive bi-square method, the reasonable bandwidth of GWR achieved was 52 . The GWR results show that using GWR reduces the AIC value by 48.2, and the adjusted R-square is raised to 0.564 , which achieves good results. From the average of the absolute values of the regression coefficients of the GWR indicators, LG has the greatest impact on PCSDI, followed by PCACCL and PCASOL. By contrast, the impacts of DRC and DRP on PCSDI are minimal.

\subsubsection{Spatial Heterogeneity Analysis on Affecting Factors}

In order to visualize the regression coefficient of the index in the GWR model, and to obtain the spatial distribution in order to further explore the spatial difference incurred by the indexes, Table 5 and Figure 11 show that location can explain the $57.62 \%$ of the share dividend per capita. In the outstanding area, the intensity of the coefficient fluctuates between 0.01 and 1.5. In the spatial distribution of the regression coefficients, the per capita share dividend and the location are absolutely and negatively correlated by $100 \%$; the closer to Guangzhou and Foshan's downtowns, the higher the dividend, 
because location has a huge impact on the usage and value of the land; the closer to the core city, the more likely it is to develop into commercial and residential areas and generate higher land rents. The rent of industrial land is also affected; the more convenient the location, the higher the rent and the occupancy rate. In addition, the outstanding areas show interesting adverse trends. For example, the income of rural communities in Dali Town shows a positive correlation between the PCSDI and LG. The reason is that a fierce competition exists between Chinese city governments, and the government is unwilling to take the initiative to develop at the edge of the city, in order to prevent the positive externalities generated by the development from spreading to neighboring cities, making the marginal community of Dali Town and Guangzhou a development subsidence area.

Table 5. The influence the coefficient of the common least square method and geographical weighted regression.

\begin{tabular}{ccc}
\hline \multirow{2}{*}{ Variables } & \multicolumn{2}{c}{ Coefficients (Standardized) } \\
\cline { 2 - 3 } & OLS & GWR \\
\hline GL & $-0.507^{*}$ & $-0.680^{\text {a }}$ (mean) \\
DRP & $0.305^{* * *}$ & $0.338^{\text {a }}$ (mean) \\
DRC & $0.241^{* *}$ & $0.341^{\text {a }}$ (mean) \\
PCASOL & $0.101^{* *}$ & $0.405^{\text {a }}$ (mean) \\
PCACCL & $0.379^{*}$ & 0.581 \\
\hline
\end{tabular}

Note: ${ }^{*}{ }^{* *}$ and ${ }^{* * *}$ indicate significance at $p<0.05,0.01$ and 0.001 . A superscript ' $a$ ' indicates that the variable is a local independent variable, and that the coefficient presented is the mean value of all of the units.

Table 6 and Figure 11 present the distribution, intensity, and direction of the coefficient values of the relationship between DPR and PCSDI. In the entire Nanhai District, only $28.10 \%$ of the rural communities are considered to have a significant relationship between this variable and PCSDI. In the outstanding region, the intensity of the coefficient fluctuates between -0.73 and 0 . In terms of the spatial distribution of the regression coefficients, PCSDI tends to be negatively correlated with DPR $(82.35 \%)$, because PCSDI is only among the local registered population; the higher the registered population density, the less the per capita collective land resource occupation, and the less the PCSDI will be. In addition, $17.65 \%$ of the communities show a positive correlation, such as Dali Town located in the east of Nanhai, Shishan Town located in the middle, and Danzao Town located in the west, because the advantageous location and the key development of Nanhai have offset the impact of the insufficient per capita resources.

DRC has an obviously different impact on Nanhai's people, especially in terms of PCSDI. The regression coefficients of the relatively underdeveloped Xiqiao, Danzao, and Lishui are generally higher than those of the developed Dali and Shishan, and mainly show a positive correlation effect $(77.14 \%)$. The reason is that the key development areas of Nanhai District-Dali (near Guangzhou) and Shishan (a key area of the national development zone) - have acquired many state-owned lands. The land acquisition for highway construction has also led to the further reduction of collective land resources, which in turn offsets the advantages of the improved location conditions brought about by the highway construction.

PCASOL can explain $33.81 \%$ of PCSDI. In the outstanding region, the intensity of the coefficient fluctuates between -0.25 and 0.89 . The per capita area of the state-owned construction land has a significant difference in the intensity of its impact on Nanhai's people in terms of PCSDI. The regression coefficients of the relatively underdeveloped Xiqiao, Danzao, and Lishui are generally higher than those of the developed Guicheng streets and Shishan Town, and mainly show a positive correlation effect $(100 \%)$, which is different from our previous assumptions. Generally speaking, the requisition of state-owned land reduces the land resource occupation, because the development of state-owned land may bring positive externalities to the development of the surrounding area. 


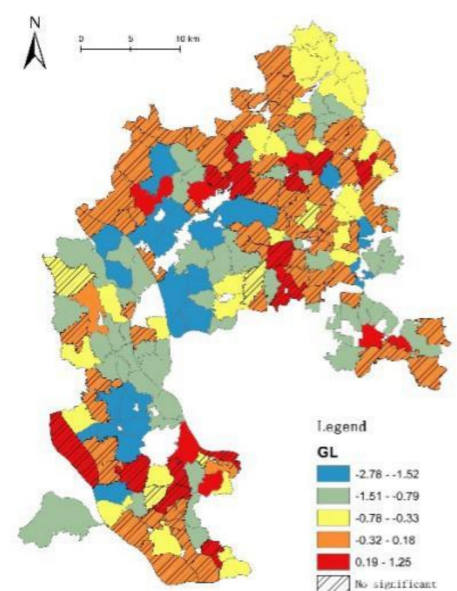

(a)

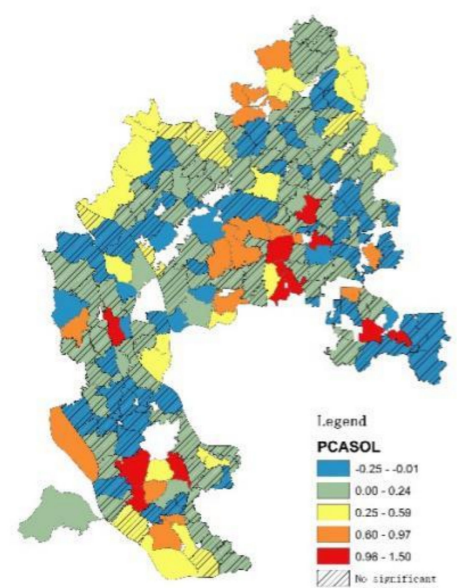

(c)

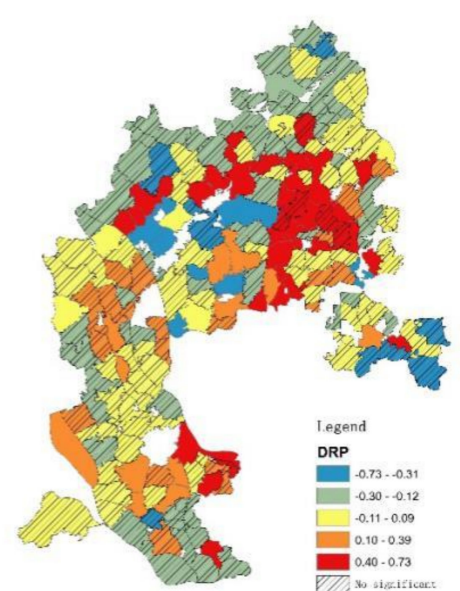

(b)

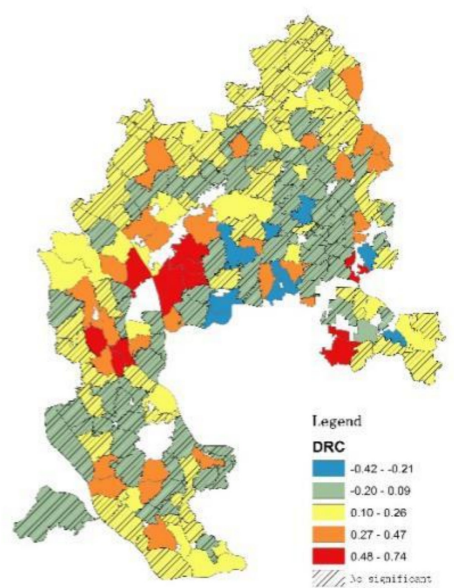

(d)

Figure 11. (a) Spatial distribution of the regression coefficients for GL, (b) Spatial distribution of the regression coefficients for DPR, (c) Spatial distribution of the regression coefficients for PCASOL, (d) Spatial distribution of the regression coefficients for DRC.

Table 6. Summary of the directions of the relationships derived from the GWR model.

\begin{tabular}{cccccc}
\hline & \multicolumn{5}{c}{ Directions of Relationship in the Multi-GWR Model } \\
\cline { 2 - 6 } & + & - & sig. $(\boldsymbol{p}<\mathbf{0 . 0 5 )}$ & + & - \\
\hline GL (km) & 16.67 & 83.33 & 57.62 & 0 & 100 \\
DRP (per/ha) & 40.48 & 59.52 & 28.10 & 82.35 & 17.65 \\
DRC (\%) & 84.76 & 15.24 & 36.67 & 77.14 & 22.86 \\
PCASOL (ha) & 69.52 & 30.48 & 33.81 & 100 & 0 \\
\hline
\end{tabular}

\section{Discussion and Conclusions}

In order to accurately measure the evolution of the temporal and spatial differences in rural residents' incomes, scholars have to reveal the influencing factors or formative mechanisms behind such differences, which is an important foundation for the reduction of the income gap between the rich and the poor, promoting the construction of a new countryside, and maintaining social stability [63]. However, several factors have to be considered. First, most of the existing research results are from economists and sociologists; thus, the causes of rural income disparities are mainly due to socioeconomic and policy aspects, and an in-depth exploration of the geographical factors is lacking. Second, the existing studies that mainly focus on large-scale research in areas above national 
and provincial levels lack in-depth discussions on small-scale spaces of homogeneous types of regions, such as semi-urbanized areas. Finally, the existing quantitative measurement of income inequality is mainly based on the spatial analysis units at the county, municipal, and higher levels, whereas the community/village scale is absent. This study contributes to previous research in three ways. First, it contributes a quantitative analysis to current rural income inequality studies, which mainly adopt qualitative methods. Second, it introduces the concept of spatial heterogeneity, and provides an in-depth investigation into the geographical causes. Third, it extends previous research by providing a community/village-scale case, and much knowledge is drawn from the local scale analysis.

This research specifically investigates income differences among rural community residents under peri-urbanized areas, and discusses the factors that affect the income difference within these communities. In order to achieve these goals, we first analyzed the distribution and spatial autocorrelation of PCSDI and PCNI. Then, we applied a GWR model in order to explore the strength and direction of the five drivers of the remarkable difference in PCSDI. The main results of this research are as follows.

In general, the PCSDI and PCNI of rural communities in Nanhai increased significantly during the 10 year period from 2007 to 2016. The PCSDI increased from 2124 RMB in 2007 to 5346 RMB in 2016, achieving more than a 2.5 times increase and an average annual growth rate of $6.0 \%$. The PCNI also increased from 10,359 RMB in 2007 to 22,276 RMB in 2016, achieving a nearly 2.2 times increase and an average annual growth rate of $5.3 \%$. Except in 2008, the urban-rural income gap continued to widen. Therefore, from the inside of the Nanhai District, rural industrialization (specifically, non-agricultural development) failed to narrow the gap between the urban and rural areas.

In terms of PCNI, whether in 2007 or 2016, eastern towns had the highest income, followed by western towns; and central towns had the lowest income. In terms of the average annual growth rate, western towns were the highest, followed by eastern towns; and central towns were the last. Guicheng, Dali, and Xiqiao were always in the top three positions during the two periods. The western town of Xiqiao took advantage of the ecological environment to find new functions in the Guangzhou-Foshan metropolitan area, and improved the income level of rural residents. Affected by the land rent value, the gradient difference of PCSDI in the east, middle, and west of Nanhai is evident. In terms of the average annual growth rate, western and central towns almost had the same average annual growth rates, with $16.3 \%$ and $16.1 \%$, respectively; eastern towns were the lowest, with only $11.1 \%$. In terms of each town, Dali, Guicheng, and Lishui were always the top three during the two periods.

The calculation of the overall correlation shows that, in 2007-2016, the spatial distribution of PCSDI and PCNI in Nanhai rural communities exhibited significant spatial clustering features. The spatial cluster of PCNI is also remarkably higher than that of PCSDI, suggesting that the spatial distribution of PCNI is more unequal than PCSDI. The spatial distribution of rural PCSDI in Nanhai has a downward trend. The Moran's I decreased from 0.4099 in 2007 to 0.3191 in 2016; that is, a 22.2\% decrease. Conversely, the spatial distribution of the clustering PCNI decreased slightly in 2014 and 2015 , but continued to increase in all of the other years. The Moran's I was 0.4517 in 2007, and increased to 0.6241 in 2016 at $38.2 \%$, indicating that the PCSDI gap was narrowing, whereas the net income gap continued to enlarge. From the point of local spatial autocorrelation, the overall dividend difference narrowed, and the reduction in $\mathrm{H}-\mathrm{H}$ units was the main reason for the narrowing of the difference. $\mathrm{H}-\mathrm{H}$ districts were mainly concentrated in Dali Town and the southern part of Shishan Town, but the number of units in Shishan Town increased significantly, whereas those in Dali Town decreased. The L-L districts were mainly concentrated in the northeastern part of Danzao Town, Xiqiao Town, and the southeast corner of Jiujiang Town; the difference in net income expanded, and the increase in $\mathrm{L}-\mathrm{L}$ units was the main reason for the expansion. Apart from Dali Town and Guicheng Street, the H-H agglomeration area added Xiqiao Town, and the number of units in Dali Town reduced significantly. The L-L district gathered in large areas of the north of Shishan Town and Lishui.

Although the difference in PCSDI decreased, the income of the collective land still accounted for $51 \%$ of the total income of the residents. Moreover, the wage income of the residents was relatively 
balanced, and PCSDI was positively correlated with the rental income of their houses. Thus, the income inequality of rural residents was still mainly reflected in the land income gap. Therefore, PCSDI was adopted to represent the overall income difference for GWR. From the average of the absolute values of the regression coefficients of the GWR indicators, LG had the greatest impact on PCSDI, followed by PCACCL and PCASOL. By contrast, the effects of DRC and DRP on PCSDI were minimal; the test results showed that LG, DRP, DRC, and PCASOL had a spatial variability which affected PCSDI, and could be set as local variables.

The spatial variation of the impact of PCACCL on PCSDI distribution was small, and should be set as a global variable. LG can explain $57.62 \%$ of PCSDI. In the significant area, the intensity of the coefficient fluctuates between 0.01 and 1.5. In the spatial distribution of the regression coefficients, PCSDI and LG were absolutely and negatively correlated (100\%). In the entire Nanhai District, only $28.10 \%$ of rural communities were considered to have a significant relationship between DRP and PCSDI. DRC had obvious differences in the intensity of its effect of PCSDI. The regression coefficients of the relatively underdeveloped Xiqiao, Danzao, and Lishui were generally higher than those of the developed Dali and Shishan, and mainly showed a positive correlation effect $(77.14 \%)$. PCASOL can explain $33.81 \%$ of PCSDI. In the significant region, the intensity of the coefficient fluctuates between -0.25 and 0.89 .

Owing to the limited availability of rural residents' income data, this study was unable to measure the income difference between the local and migrant populations in the community. Compared with local residents, migrants can neither enjoy community welfare due to their non-local identity, nor can they have the right to choose advantageous jobs. They are in a relatively weak position in selecting jobs that cannot benefit the sustainable social development in peri-urbanized areas. In addition, socioeconomic indicators at the community level are currently unavailable, which prevents a comprehensive quantitative analysis of the geographical and socioeconomic factors that affect income differences in rural communities. With the improvement of data availability in the future, the further investigation of the income differences between migrants and locals, including the comparison of socioeconomic impact factors and geographical factors, is necessary.

Author Contributions: P.B. and Q.Y. conceived and designed the research; Z.X. conducted this research, analyzed the data, and wrote the manuscript; P.B. revised and reformatted the overall paper. All authors have read and agreed to the published version of the manuscript.

Funding: This research received no external funding.

Acknowledgments: The authors are thankful to two anonymous reviewers for their helpful comments. They also appreciate Shaojian Wang from Sun Yat-sen University, for his warm guidance in manuscript revision. The thanks also go to Junwen Lu's help throughout the process of manuscript writing and revision.

Conflicts of Interest: The authors declare no conflict of interest.

\section{References}

1. Hussain, A.; Lanjouw, P.; Stern, N. Income inequalities in China: Evidence from household survey data. World Dev. 1994, 22, 1947-1957. [CrossRef]

2. Lee, J. Changes in the source of China's regional inequality. China Econ. Rev. 2002, 11, 232-245. [CrossRef]

3. Liu, H. Factor decomposition of rural regional income inequality changes in China. Acta Geogr. Sin. 2008, 8, 799-806. [CrossRef]

4. Zhou, Y.; Qin, Y. Income inequality of Chinese rural resident and the factors which impact it. In Empirical Analysis on Income Inequality of Chinese Residents; Springer: Berlin/Heidelberg, Germany, 2012; pp. 87-123.

5. McGee, T. The Spatiality of Urbanization: The Policy Challenges of Mega-Urban and Desakota Regions of Southeast Asia. Available online: http://citeseerx.ist.psu.edu/viewdoc/download?doi=10.1.1.548.2985\&rep= rep1\&type $=$ pdf (accessed on 11 October 2020).

6. Zheng, Y.; Liu, S.; Chen, T. The characteristics of peri-urbanization region: A case study of Dongguan municipality in Guangdong province. Geogr. Res. 2003, 29, 1577-1583. 
7. Liu, S.; Chen, T.; Cai, J. Peri-urbanization in China and its major research issues. Acta Geogr. Sin. 2004, 59, 101-108.

8. Ravetz, J.; Fertner, C.; Nielsen, T.A.S. The Dynamics of Peri-Urbanization; Springer: Berlin/Heidelberg, Germany, 2013.

9. Shatkin, G. The real estate turn in policy and planning: Land monetization and the political economy of peri-urbanization in Asia. Cities 2016, 53, 141-149. [CrossRef]

10. Odame, A.D.; Tia, B.J.; Kwabena, F.E.; Kojo, B.P. Determinants of peri-urbanization and land use change patterns in peri-urban Ghana. J. Sust. Dev. 2014, 7, 95-109.

11. Zhu, J.; Hu, T. Disordered land rent competition in China's peri-urbanization. Soc. Sci. Electron. Publ. 2008. [CrossRef]

12. Wei, H.; Yi, J.; Zhang, J. Inequality and internal migration in China: Evidence from village panel data. Hum. Dev. Res. Pap. 2009, 27, 2009.

13. Fulong, W.U. Land development, inequality and urban villages in China. Int. J. Urban. Reg. Res. 2010, 33, 885-889.

14. Yan, G.; Zhigang, L.I.; Guoen, W.; Qifeng, Y. Social equity between villages under capitalization of collectively-owned land and its impact on urban inclusivity. Urban Dev. Stud. 2016, 4, 12.

15. Kontgis, C.; Schneider, A.; Fox, J.; Saksena, S.; Spencer, J.H. Monitoring peri-urbanization in the greater Ho Chi Minh city metropolitan area. Appl. Geogr. 2014, 53, 377-388. [CrossRef]

16. Aguilar, A.G. Peri-urbanization, illegal settlements and environmental impact in Mexico City. Cities 2008, 25, 133-145. [CrossRef]

17. Barros, J.; Tavares, A.; Monteiro, M.; Santos, P. Peri-urbanization and rurbanization in Leiria city: The importance of a planning framework. Sustainability 2018, 10, 2501. [CrossRef]

18. Briggs, J.; Mwamfupe, D. Peri-urban development in an era of structural adjustment in Africa: The city of Dar es Salaam, Tanzania. Urban Stud. 2000, 37, 797-809. [CrossRef]

19. Díaz-Chavez, R. Measuring sustainability in peri-urbanized area. In The Peri-Urban Interface in Developing Areas: Approaches to Sustainable Natural and Human Resource Use; Routledge: Abingdon, UK, 2012.

20. Dupont, V. Conflicting stakes and governance in the peripheries of large Indian metropolises-An introduction. Cities 2007, 24, 89-94. [CrossRef]

21. Mbiba, B.; Huchzermeyer, M. Contentious development: Peri-urban studies in sub-saharan africa. Prog. Dev. Stud. 2014, 2, 113-131. [CrossRef]

22. Webster, D. On the Edge: Shaping the Future of Peri-Urban East Asia; Citeseer: Princeton, NY, USA, 2002.

23. Simon, D. Urban environments: Issues on the peri-urban fringe. Annu. Rev. Environ. Resour. 2008, 33, 167-185. [CrossRef]

24. Zhao, P. Too complex to be managed? New trends in peri-urbanisation and its planning in Beijing. Cities 2013, 30, 68-76. [CrossRef]

25. Lin, G.C.S. Peri-urbanism in globalizing China: A study of new urbanism in Dongguan. Eurasian Geogr. Econ. 2006, 47, 28-53. [CrossRef]

26. Zhao, P.; Lü, B.; Woltjer, J. Conflicts in urban fringe in the transformation era: An examination of performance of the metropolitan growth management in Beijing. Habitat Int. 2009, 33, 347-356. [CrossRef]

27. Zhou, Y.; Logan, J.R. Growth on the Edge: The New Chinese Metropolis; Blackwell Publishing Ltd.: Hoboken, NJ, USA, 2008.

28. Webster, D.; Muller, L. Challenges of Peri-Urbanization in the Lower Yangtze Region: The Case of the Hangzhou-Ningbo Corridor; Asia/Pacific Research Center: Stanford, CA, USA, 2002; Available online: https://fsi-live.s3.us-west-1.amazonaws.com/s3fs-public/Webster-Muller.pdf (accessed on 11 October 2020).

29. Jieming, Z. Coordinated urban-rural development: Urban integrity and rural autonomy. Urban Plan. Forum 2013, 44, 10-17.

30. Yunez-Naude, A.; Edward Taylor, J. The determinants of nonfarm activities and incomes of rural households in Mexico, with emphasis on education. World Dev. 2001, 29, 561-572. [CrossRef]

31. Zhang, J.; Giles, J.; Rozelle, S. Does it pay to be a cadre? Estimating the returns to being a local official in rural China. J. Comp. Econ. 2012. [CrossRef]

32. Adams, J.; Richard, H. Nonfarm income, inequality, and land in rural Egypt. Econ. Dev. Cult. Chang. 2002, 50, 339-363. [CrossRef] 
33. Gustafsson, B.; Shi, L. Income inequality within and across counties in rural China 1988 and 1995. J. Dev. Econ. 2003, 69, 179-204. [CrossRef]

34. Enke, S. Economic development with unlimited and limited supplies of labour. Oxf. Econ. Pap. 1962, 14, 158-172. [CrossRef]

35. Sheppard, E. Economic theory and underdeveloped regions. Reg. Stud. 2017, 51, 1-2. [CrossRef]

36. Benjamin, D.; Brandt, L.; Glewwe, P.; Guo, L. Markets, Human Capital and Inequality: Evidence from Rural China; Palgrave Macmillan: London, UK, 2002.

37. Jensen, F.E. The farm credit system as a government-sponsored enterprise. Rev. Agric. Econ. 2000, 22, 326-335. [CrossRef]

38. Bateman, I.J.; Langford, I.H.; Turner, R.K.; Willis, K.G.; Garrod, G.D. Elicitation and truncation effects in contingent valuation studies. Ecol. Econ. 1995, 12, 161-179. [CrossRef]

39. Patton, M.; Kostov, P.; Mcerlean, S.; Moss, J. Assessing the influence of direct payments on the rental value of agricultural land. Food Policy 2008, 33, 397-405. [CrossRef]

40. Davis, K.; Nkonya, E.; Kato, E.; Mekonnen, D.A.; Odendo, M.; Miiro, R.; Nkuba, J. Impact of farmer field schools on agricultural productivity and poverty in east Africa. World Dev. 2010, 40, 402-413. [CrossRef]

41. Mathijs, E.; Noev, N. Subsistence farming in central and eastern europe: Empirical evidence from Albania, Bulgaria, Hungary, and Romania. East. Eur. Econ. 2004, 42, 72-89. [CrossRef]

42. Kan, I.; Kimhi, A.; Lerman, Z. Farm output, non-farm income and commercialization in rural Georgia. Discuss. Pap. 2006, 3, 276-286.

43. Hare, D. 'Push' versus 'pull' factors in migration outflows and returns: Determinants of migration status and spell duration among China's rural population. J. Dev. Stud. 1999, 35, 45-72. [CrossRef]

44. Knight, J.; Song, L. The spatial contribution to income inequality in rural China. Camb. J. Econ. 1993, 17, 195-213. [CrossRef]

45. Chen, S.; Ravallion, M. Data in transition: Assessing rural living standards in southern China. China Econ. Rev. 1996, 7, 23-56. [CrossRef]

46. Lee, C.K.; Selden, M. China's durable inequality: Legacies of revolution and pitfalls of reform. Jpn. Focus 2007, 21, 75-91.

47. Brun, J.F.; Combes, J.L.; Renard, M.F. Are there spillover effects between coastal and noncoastal regions in China? China Econ. Rev. 2002, 13, 161-169. [CrossRef]

48. Wan, G. Accounting for income inequality in rural China: A regression-based approach. Econ. Res. J. 2004, 32, 348-363. [CrossRef]

49. Rozelle, S. Rural industrialization and increasing inequality: Emerging patterns in China' s reforming economy. J. Comp. Econ. 1994, 19, 362-391. [CrossRef]

50. Rozelle, S. Stagnation without equity: Patterns of growth and inequality in China's rural economy. China J. 1996, 35, 63-92. [CrossRef]

51. Luo, X.; Zhu, N. Nonfarm activity and rural income inequality: A case study of two provinces in China. Policy Res. Work. Pap. 2010. [CrossRef]

52. Griffin, K.; Saith, A. The Pattern of Income Inequality in Rural China. Oxf. Econ. Pap. 1982, 34, 172-206. [CrossRef]

53. Wang, Y. A model of industrialization and rural income distribution. China Agric. Econ. Rev. 2019, 11, 507-535. [CrossRef]

54. Ding, J.; Salinas-Jiménez, J.; Salinas-Jiménez, M.d.M. The impact of income inequality on subjective well-being: The case of China. J. Happiness Stud. 2020, 1-22. [CrossRef]

55. Foltz, J.; Guo, Y.; Yao, Y. Lineage networks, urban migration and income inequality: Evidence from rural China. J. Comp. Econ. 2020, 48. [CrossRef]

56. Ran, M.; Chen, L.; Li, W. Financial deepening, spatial spillover, and urban-rural income disparity: Evidence from China. Sustainability 2020, 12, 1450. [CrossRef]

57. Zhu, J.; Guo, Y. Rural development led by autonomous village land cooperatives: Its impact on sustainable China's urbanisation in high-density regions. Urban Stud. 2015, 52, 1395-1413. [CrossRef]

58. Guo, Y.; Xiao, Y.; Yuan, Q. The redevelopment of peri-urban villages in the context of path-dependent land institution change and its impact on chinese inclusive urbanization: The case of Nanhai, China. Cities 2016, 60, 466-475. [CrossRef] 
59. Chen, F.; Davis, J. Land reform in rural China since the mid-1980s. Land Reform Land Settl. Coop. 1998, 6, 123-137.

60. Samuel, P.S.H.; Lin, G.C.S. Emerging land markets in rural and urban China: Policies and practices. China Q. 2003, 175, 681-707.

61. Tobler, W.R. A computer movie simulating urban growth in the Detroit region. Econ. Geogr. 1970, 46, $234-240$. [CrossRef]

62. Anselin, L. Local indicators of spatial association-LISA. Geogr. Anal. 2010, 27, 93-115. [CrossRef]

63. Le, Z.; Chuanqing, L.; Huan, Z.; Xiaobo, H. Multilevel modeling of rural livelihood strategies from peasant to village level in Henan province, China. Sustainability 2018, 10, 2967.

(C) 2020 by the authors. Licensee MDPI, Basel, Switzerland. This article is an open access article distributed under the terms and conditions of the Creative Commons Attribution (CC BY) license (http://creativecommons.org/licenses/by/4.0/). 